Article

\title{
Virtual Placements to Develop Employability Skills for Civil and Environmental Engineering Students
}

\section{Parneet Paul}

Water Sustainability Research Centre, Department of Mechanical, Aerospace, and Civil Engineering, Brunel University London, Uxbridge, Middlesex UB8 3PH, UK; E-Mail: parneet.paul@brunel.ac.uk; Tel.: +44-1895-265-435; Fax: +44-1895-274-000

Academic Editor: James Albright

Received: 11 December 2014 / Accepted: 20 March 2015 / Published: 2 April 2015

\begin{abstract}
This project work addresses the crucial need to encourage undergraduate civil and environmental engineering students to gain employment skills and training right from the start of their studies so that their overall employability increases; their confidence level in networking with industry and within the workplace increases; and so that they are successfully able to obtain employment after finishing their studies. This initiative is a stepping-stone employability exercise which focuses specifically on first year students to help them engage with industry right from the start of their course. It is proposed that they would gain some realistic work experience both individually and as part of group within a virtual work environment using an action learning approach. The virtual environment used was based on SecondLife, a popular virtual reality programme. A pilot scheme was set up and run at Brunel University during the summer of 2014 using eight self-selecting first year students. The scheme's outputs were extensively monitored and evaluated to assess its impact on the development of employability skills. This approach may prove a cost effective way of letting students gain an insight into the workplace whilst improving these skills. It may also prove a way for employers to select from a large range of students the best to actually undertake their real work-based internships.
\end{abstract}

Keywords: virtual; placement; employability; skills; undergraduate 


\section{Introduction}

\subsection{Project Objectives and Key Deliverables}

The project work described in this paper addresses the crucial need to encourage undergraduate civil and environmental engineering students to gain employment skills and training from the first year of their studies so that their overall employability increases; their confidence level in networking with industry and within the workplace increases; and, so that they are successful in being able to obtain summer placements and/or sandwich placements whilst studying at a UK University. The overarching aim is that all students, whether they chose to undertake a sandwich placement year (if available as an option on their course of studies) and successfully obtain one or not, leave their higher education establishment with some relevant work experience. This is since employers are increasingly expecting undergraduate civil and environmental engineering students to already have some relevant work experience before joining them as it partially demonstrates their ability to interact effectively in the workplace [1,2]. It also demonstrates networking ability and other positive transferrable skills in being able to obtain and successfully complete a work-based placement or training opportunity.

Consequently this project work basically enhances the learning and teaching strategy of a University by including action learning as an optional mode of study for students during their summer period. It also engages them and increases their employability by enhancing the overall student experience. It also begins to tackle the difficult issue of how to get students rapidly into the workplace on completion of their studies (i.e., successfully applying for and obtaining employment).

Thus the key long term aims of this project work are:

- To encourage more students to go on placements (or undertake training opportunities as and when they are available).

- To give placements to those students who otherwise would not have one even if virtual ones.

- Long term wise, to boost the employability skills, behaviour and attitude of students.

As part of an existing Professional Development module within Brunel University's Civil Engineering Division, one of the key deliverables in this scheme was the development and implementation of a coherent and integrated summer placement strategy for first year undergraduate civil and environmental engineering students. Part of this strategy was to formally help students to gain confidence and networking abilities to allow them to obtain their own year long duration sandwich placements during their third year. This process occurs, usually naturally, with either high achieving, highly self-motivated and/or older students who only need limited support and encouragement in this area. However, the majority of a standard first year student intake usually need greater levels of coaching and support. Thus this scheme would use action learning as a tool to help unsuccessful students to gain invaluable virtual employment experience, while also developing their self-confidence in being able to interact with professional engineers, and improve their overall networking skills. The other major deliverable of this scheme was the development of high quality, relevant training material for the pilot phase of the project that was used in an action learning context. It also included the development of synoptic tests to gauge the effectiveness of this action learning initiative; and the 
development of Likert-type questionnaires to elicit the response from students, potential employers as sponsors, and academics alike to this scheme.

\subsection{Importance of Employability Skills Development}

The UK Institute of Directors has identified some generic employability skills that many UK employers are seeking in recent graduates. They are: ability to work in teams; good communication skills including literacy and numeracy skills; good time keeping; ability to meet deadlines; honesty, integrity, reliability and conscientiousness [3]. On top of these generic skills, most international technical/engineering employers require further specific skill sets from prospective graduate engineers including amongst others: engineering problem solving and decision making skills; ability to apply knowledge of science and engineering principles; and, competence in a specific engineering discipline [4].

Even though the current economic climate has been improving and the projected long term forecast for new job creation is starting to become more positive, undergraduate civil and environmental engineering students still need to be given a greater sense of urgency and personal ownership with regard to obtaining secure graduate employment once they have completed their studies. This is since the numbers of traditional graduate engineering roles are diminishing in the UK due to globalisation [5]. In fact employers in India cite that their main employability skill they need in newly graduated engineers is ability to communicate effectively in English as a considerable amount of their work is internationally based and tendered [6]. This means that almost from the first day of enrolment on their course, UK undergraduate civil and environmental engineering students need to start thinking about how to improve they employability in order to compete with their local and international counterparts [7]. They also need to start to link up with potential employers in order to ascertain what their requirements are when they recruit for graduate engineers $[8,9]$.

Hence the initiative described in this paper is a stepping-stone employability exercise which focuses specifically on first year students to help them engage with industry right from the beginning of their undergraduate course. It is proposed that they would gain some realistic work experience either individually or as part of group within a virtual workplace environment using an action learning approach. It is crucial to note here that this scheme is not intended to replace an actual work-based summer placement or internship or training opportunity, but would simple be used to supplement and augment the possible options open to first year students, especially for those who lack confidence, maturity or the networking ability required to successfully obtain a work-based summer placement or internship or training opportunity [10,11]. Thus it could be thought of a as a stop-gap measure for this type of student, and could be used to develop these students competence in these shortfall areas [12].

The ideas proposed in this initiative have already been approved in principle by the Industrial Advisory Panel (IAP) of the Brunel University’s Civil Engineering Division. This panel is primarily made up of a spectrum of civil engineering employers and industrialists such as personnel from Arups, Atkins, Halcrow, AMEC, etc., who advise on the industrial appropriateness of the Divisional courses offered and on their actual content and structuring as well. Overall, the IAP seemed keen to get involved in schemes of this type since it did not require huge resources from them, although there was concern that a scheme of this nature could not replace an actual work-based placement but could simply act as a stepping stone to obtaining one. 


\subsection{Virtual Internships}

A revolution has occurred in the last few years where computer technologies have been used to create graphically-rendered, three dimensional spaces in which multiple users interact, create content and collaborate synchronously [13]. They are called virtual worlds. The academic community has shown great interest in these virtual worlds as a potential educational technology and subsequent research publications in this area have grown exponentially [14]. In addition to numerous international institutions, most UK universities now have a strong presence in one or more virtual worlds [15].

A lot of recent research work has focused on using these virtual worlds for teaching and supporting student centred learning [16]. This has posed its own unique opportunities and challenges. Some countries like the USA are already leading the way in using these virtual spaces for training staff in complex workplace issues and scenarios commonly encountered in high pressure environments but without any health and safety ramifications needing to be invoked. Thus the concept of virtual internships has been used via clinical simulations to train inexperienced nurses in basic diagnosis using signs and symptoms methodology without putting any real patients at risk [17]. This training can also be extended to the triaging of simulated patients in complex emergency room scenarios.

This experiential learning through "real” world placements undertaken in three dimensional virtual world spaces has been expanded upon in recent times, largely by industries that are keen to embrace technology if it can lead to more efficient, cost effective staff training [18]. Consequently many so called virtual internships now exist within North America in the fields of technology, business, journalism, and various forms of research. Companies have found that having the capability to use the internet, email communications, and a cell phone makes the need for a traditional office unnecessary in many instances. This means working remotely by using technology at the intern's convenience and with no daily commuting requirement. In the case of a UK university, this should prove especially useful for first and second year students who still need to gain knowledge, skill, and understanding of a particular industry. It also makes sense for small companies and start-ups in the USA who then don't have to find the physical space for an extra person and the associated costs of managing a work-based intern. Although the structure of virtual internships in USA may be different from that of traditional work-based internships, the application process is usually pretty similar [19].

Broadly speaking a virtual internship provides the opportunity for individuals to work from anywhere at any time [20]. In some industrial sectors, the rise of technology has greatly limited the need for employees or interns to interact on a face-to-face basis, and has reduced the need that they be located in a specific physical space at a specific period of time. The internet affords people the opportunity to be able to do work from remote locations, including their dorm room or home. It means that overseas students studying at a UK higher education institution who usually return home during the summer [21], and those working in seasonal employment (such as bar work to pay off their students loans), are not as disadvantaged, since they can still gain some useful experience, albeit remotely via the internet.

\subsection{Action Learning Approach}

The idea of these virtual summer placements and internships comes under the wider area of action learning. Action learning involves working on real problems, and focuses on real learning and actually 
implementing solutions [22,23]. It has now become a well-known method of learning since Professor Reg Revans introduced the concept shortly after the Second World War. It is a method of collaborative learning where a small group of learners known as an "action learning set" meet often to reflect on real work problems. The basic philosophy behind it is that the most effective learning takes place when students are faced with a real problem to solve [24-26].

At the moment little or no action learning techniques are currently used in Brunel University's Civil Engineering Division. Some problem based learning is used especially in the final year of the MEng course that has a significantly weighted group project which is assessed collectively and individually. Some other modules due use problem based learning as well particularly modules orientated towards teaching design engineering. The major difference between action learning as opposed to the commonly used problem based learning approach is that the aim of an action learning set is to focus on the individual and their future action including specifically their personal learning achieved and reflection on it $[26,27]$. Therefore it is more flexible, open-ended learning approach and suited to a work place/internship environment rather than a traditional class room set up that can accommodate traditional problem based learning [26,27].

\subsection{Virtual Reality Environment-SecondLife}

SecondLife is a web-based virtual reality programme. It is freely available at no cost (www.SecondLife.com). It creates a three dimensional environment in which participants can control the movement of an avatar, interacting with other participants through both sight and sound. These avatars are a personalised representation of the participant in the virtual SecondLife world. In terms of its usage in UK universities, it is the predominant virtual world used for educational purposes [28]. Consequently it has been naturally proposed to use this environment to create a virtual internship space that could be geared towards meeting the objectives of this project.

Some higher education establishments have tried implementing similar schemes as proposed in this study with varying degrees of success. For instance at the University of Southampton, educational professionals have tried using SecondLife as a pedagogic tool in the postgraduate teaching of gerontology and other policy relevant social sciences [29]. In fact, Linden Lab in California, USA who are the original creators of SecondLife are now actively encouraging its usage as a virtual work place tool to be used alongside real tools in the office or workplace [30]. Its wide spread usage has not taken off for a variety of reasons, some due to institutional resistance, others due to cost, while most are due to technical and logistical issues $[15,16]$. Thus usage of SecondLife can be difficult to implement in practice in an educational environment as experienced by some UK universities who have tried using it for student-led research and teaching [28]. Common complaints raised by academics trying to make use of SecondLife for similar purposes to this project are the experiencing of slow PC graphical and processing speeds and the subsequent slowed down ability to update the viewer software.

\section{Methodology}

The basic methodology was to develop realistic as possible materials that would allow interested students to undergo a virtual summer placement. This meant ideally getting on board at a very early stage a main sponsoring employer to act as the virtual internship company. The first part of this 
process involved the development of easy to use and easily understandable text based material as placement assignments which were to be delivered via email and other existing technology interfaces. After the initial pilot phase of this scheme in summer 2014 involving up to eight selected students (who would also form part of the project's “Action Learning Material's Development and Feedback Committee”), it was envisaged that this material would be fully worked up to full audio-visual capabilities with Skype conferencing; pre-recorded videos of mock meetings, site visits, etc. This would then be trialed at a much larger phase involving up to a thirty selected first year students for the following year. During this second phase of the scheme development, the students would actually be assessed by having to eventually do a final presentation to a "live" audience of industry professionals as Clientele who then judge which should be offered actual work-based placements or internships for the following year. This offer of two or three actual placements (possibly shadowing senior engineers) would act as the "carrot" to allow scheme take-up and create competition amongst interns. Most of professionals used could be sourced from the Brunel University’s IAP.

In this regard, all placement material developed would be passed to the sponsoring company for comment and modification. After successful implementation of this second phase, the third and final phase (which is outside the scope of this paper) would involve the development of a virtual learning environment as a placement using the virtualBrunel platform and the SecondLife interface [31,32]. The resource personnel developing all this material would also need to "scaffold" in this initial development work into the existing Professional Development module so that students were briefed on the expectations of this placement scheme. This would ensure they engaged from the beginning in a competitive spirit.

\subsection{Pilot Scheme Material}

As a first step a pilot virtual placement scheme was set up in summer 2014 with a small group of volunteer students from year one of the undergraduate civil engineering course. The specific objectives of the initial pilot scheme were:

- To investigate mechanisms for operating the scheme;

- To generate material for use in the scheme;

- To gain feedback from students;

- To assess the efficacy of the scheme.

Engineering consultants with experience of graduate training within the work-place were used by the Civil Engineering Division to develop the virtual internship material and also to act as the scheme tutor's during the pilot scheme period. They also generated the resources needed to carry out the evaluation of the individual student performance and the overall effectiveness of the scheme. They also mocked up a fictitious company, namely Brunel Environmental Engineering Ltd, under the pilot phase to act as the scheme's sponsoring employer. Typical "virtual” assignments, which are similar to those encountered by graduate engineers in a civil engineering consulting or contracting firm, were developed by the resource personnel as part of the fictitious company's requirements when it implemented a fictitious but realistic engineering project. Typical tasks sets as part of this project involved: 
- Team working;

- Arranging meeting times;

- Producing agendas and minutes of formal project team meetings;

- Letter and report writing;

- Application of engineering principles;

- Cost estimation;

- Information gathering.

Other typical tasks that were set got students involved in basic contract negotiations and basic design work both individually and as part of a small team. They were also involved in basic research work and technical specifications development. The aim of these assignments (to be submitted by various deadlines) was to help them to start to think like an engineer, and also to gain a prospective on what actually goes on in a design office, a contractors office, on site, etc., especially at the graduate engineer level. Some of the tasks were quite mundane or even trivial (e.g., pipe sizing calculations, basic sketching, writing memos, etc.), so that it replicated quite well the level of responsibility given to junior engineers in their first year of employment. It was recognised that some students already had their summer well mapped out so that any delivered assignments were well interspersed over the virtual placement period.

\subsection{Pilot Scheme Evaluation and Assessment}

During the pilot phase synoptic test questionnaires were used to measure the five key skills that employers are looking for in graduates [2,33], and which this scheme wishes to enhance during the action learning placement. These five skills are:

- Communication skills;

- Team behavior;

- Commercial awareness;

- Interpersonal skills;

- Problem solving and analytical skills;

Thus the key deliverables envisaged for this pilot scheme were:

- Synoptic tests and questionnaires;

- Project assignment material development under:

- Initial pilot phase;

- Extended full scale phase (beyond the scope of this project).

- Development of internet-based framework to allow the creation of a virtual learning environment as a summer placement.

\subsection{Pilot Scheme Implementation}

During the spring term, all the year one civil and environmental engineering undergraduates were informed of the pilot scheme with volunteers being actively sought. Initially eight students expressed a strong interest in partaking. In May the prospective eight volunteers were invited to a meeting during 
which they were introduced to the scheme and provided with a written brief and programme of tasks. Supporting documentation had been uploaded onto Brunel University's student interface platform known as Blackboard Learn which is standard software package used by higher education institutions to interface via the internet (or a campus intranet) with students. Since the interns on the pilot scheme mostly were returning home during the summer recess (with in some cases this being outside the UK), and many of them scheduled to take up some form of summer employment (other than suitable placements) or to carry out holiday travel, meetings themselves needed to be "virtual" and were not always during normal office hours. For this reason, use of the virtual, web-based facility called SecondLife was also investigated under this pilot scheme. Brunel University along with many UK Universities already supports SecondLife, and the Design Department has already created a virtual populated space within it known as virtualBrunel.

\subsection{VirtualBrunel within SecondLife}

Dr Olinkha Gustafson-Pearce of the Design Department produced within the virtualBrunel space of SecondLife, a full campus replica of the University buildings as shown in Figure 1. Under this pilot scheme, Dr. Gustafson-Pearce created a specific area for the fictitious company, Brunel Environmental Engineering Ltd., with a complete set of offices, drawing rooms, meeting rooms and furniture in which participants could hold a virtual meeting shown in Figures 2 and 3. This area within SecondLife was set up to be accessible only to invited participants. During the pre-scheme briefing meeting, volunteer interns were introduced to SecondLife and virtualBrunel, and given access to a secure area within it as an office facility that had been created by Brunel University's Design Department. Each of the volunteer interns was provided with a copy of Brunel University's Conditions and Guidelines for using SecondLife in a safe and acceptable manner. In order to access this virtual world in SecondLife, participants needed a lap-top or desk-top based computer with a reasonable specification graphics card, an internet access point and a microphone and speaker headset.

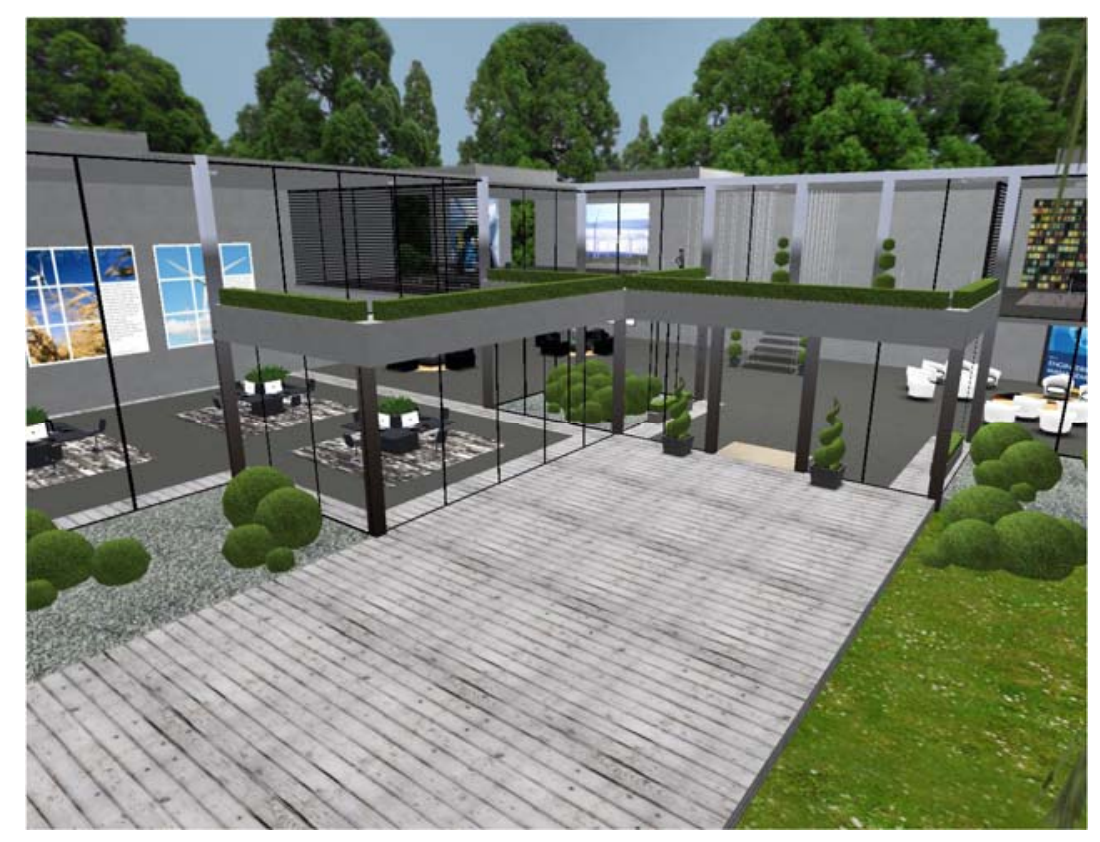

Figure 1. Screenshot of virtualBrunel campus space in SecondLife. 


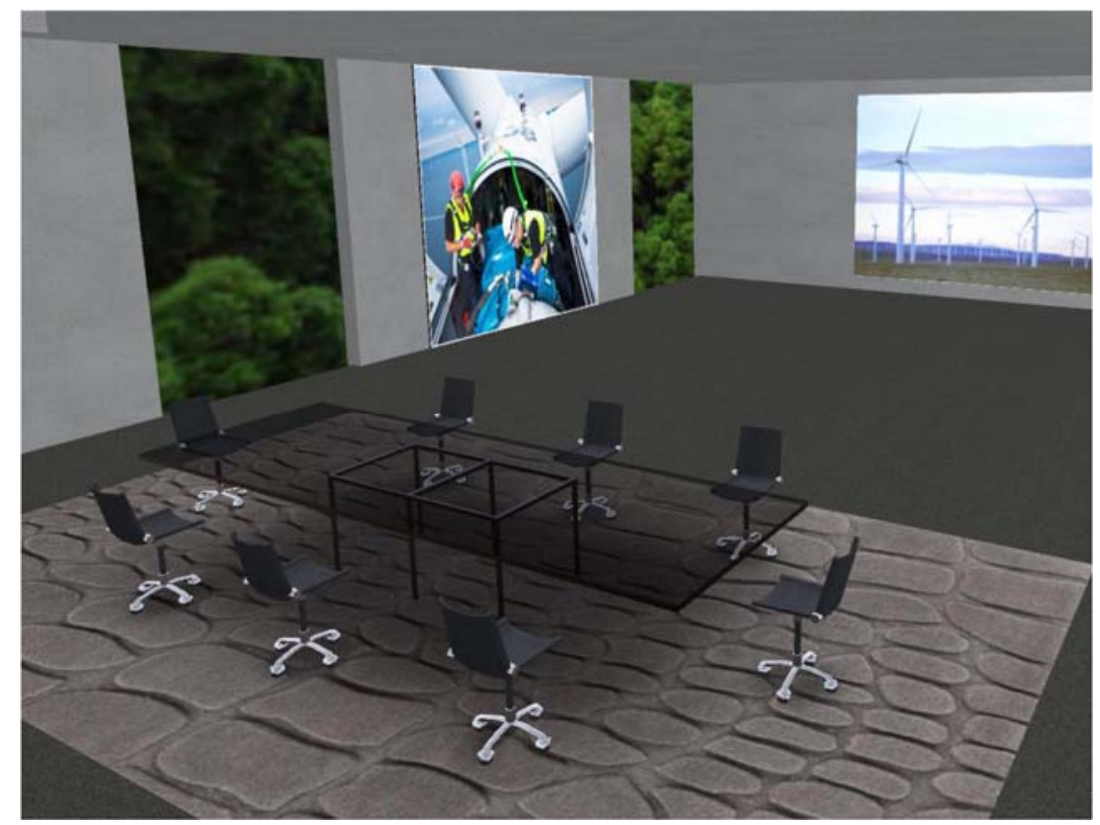

Figure 2. Screenshot of virtualBrunel meeting space created under the pilot scheme.

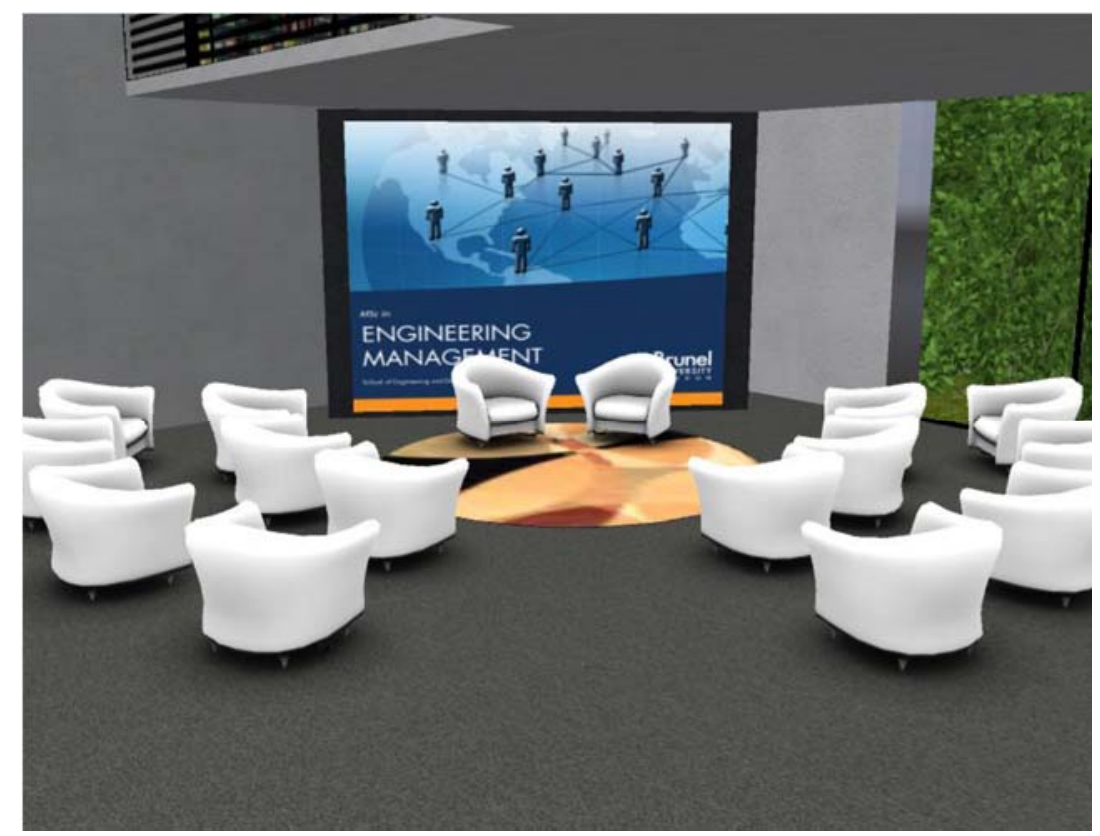

Figure 3. Screenshot of an alternative virtualBrunel meeting space created under the pilot scheme.

\subsection{The Internship Project}

A realistic UK-based construction project was conceived in which up to eight interns would carry out initial investigative tasks followed by actual design work. The project was formulated so that it operated as closely as possible to a real internship with interns being given a range of administrative and technical tasks to carry out according to a strict programme overseen by a mentor, which under the pilot phase was the engineering consultant hired to produce the virtual material and to implement the pilot scheme. The scheduled project work represented about two weeks in a real internship programme in terms of hours, but was spread out over the summer recess so that virtual internees did not feel overwhelmed. The interns worked as a team but each also had individual responsibilities. Regular 
virtual project group meetings were held within the SecondLife environment. Project documents were distributed electronically. The scheme was originally scheduled to run from around the first week of July until the end of September 2014.

The construction project devised involved the preliminary design of two new-build hotels in the UK as part of a planning application to the relevant local planning authorities. The fictitious multidisciplinary engineering consultancy firm, Brunel Environmental Engineering Ltd., had been commissioned by the developer to produce information which would be included in planning application documents. The intention was to create a project that mimicked an actual planning application and so introduce the interns to the real world of planning regulations as the first stage in any construction project.

The hotel designs were based on actual floor plans and specifications as used by a well-known chain of budget hotels. Real development sites were found local to Brunel University (that the interns were encouraged to visit) in Central London and Slough in Berkshire chosen to reflect different local planning regulations. The interns were employed by the fictitious consultants, working under the supervision of one of their directors. They were asked to investigate features and supporting services within the two construction projects that were closely related, highly topical, subject to planning and construction regulations, and likely to be encountered by many civil and environmental engineers in practice. These features and aspects of the project were:

- Incorporation of green/brown roofs in the design;

- Use of Sustainable Urban Drainage Systems (SUDS);

- Installation of grey-water recycling systems;

- Use of low environmental impact construction materials;

- Impact of the above on the developer's minimum BREEAM rating requirement.

Technical details and documentation were provided on each of the above, aspects of the project, (including a preliminary BREEAM assessment report), together with links to other web-based information including suppliers and manufacturers details. Documents and web-links were also provided relating to the actual planning policies of the two local planning authorities responsible for the two locales.

\subsection{Operation of the Pilot Scheme}

In July and August of 2014, a series of virtual group progress meetings were held in SecondLife, chaired by the company "director" (the engineering consultant/tutor hired to manage the pilot scheme). These were treated as formal project progress meetings complete with agenda and minutes. Interns were given specific tasks that are intended to reflect the aims and objectives set out in Table 1 . Feedback was provided on all the work undertaken by the interns.

Of the eight students who attended the initial pre-scheme briefing meeting in May:

- One failed to respond after that;

- Two dropped out of the scheme early on due to personal and employment commitments. One of these students had returned to Zimbabwe for the summer; 
- As the scheme progressed, two found involvement difficult due to heavy employment commitments and subsequently did not complete all set tasks. One of these students had returned to Poland for the summer and was working in the construction sector there;

- Three showed a high level of commitment throughout the duration of the pilot scheme and completed most of the set tasks;

- Six attended the feedback session in October (one of whom had previously dropped out of the scheme early on).

Table 1. Summary of virtual internship tasks set and objectives achieved.

\begin{tabular}{cc}
\hline Task & Objective \\
\hline Produce an agenda for the meeting. & $\begin{array}{c}\text { Introduce intern to structure of formal meetings as } \\
\text { used in industry and the need for agreed agenda to } \\
\text { assist in effective management of meeting. }\end{array}$ \\
\hline Produce minutes of the meeting. & $\begin{array}{c}\text { Introduce intern to need to keep accurate minutes of } \\
\text { meetings including actions arising. }\end{array}$ \\
\hline $\begin{array}{c}\text { Investigate design features (as above). } \\
\text { Write letters to manufacturers } \\
\text { seeking information. }\end{array}$ & $\begin{array}{c}\text { Introduce interns to some of the sustainability issues } \\
\text { and national planning policies and regulations. }\end{array}$ \\
\hline $\begin{array}{c}\text { Utilise a simple spreadsheet to } \\
\text { organise possible meeting times. }\end{array}$ & Develop formal communication skills. \\
\hline $\begin{array}{c}\text { Produce an individual interim report } \\
\text { relating to feasibility of design } \\
\text { features (as above). }\end{array}$ & Introduction to spreadsheets. \\
\hline $\begin{array}{c}\text { Include within the report outline } \\
\text { costing of the recommended solutions. }\end{array}$ & Introduce intern to importance of costing and to \\
\hline Produce single composite report. & Develop simple costing techniques. \\
\hline
\end{tabular}

\section{Results and Discussion}

\subsection{Evaluation and Assessment of Pilot Scheme}

After the pilot scheme finished and following the return of the volunteer interns to the main campus in October, a face-to-face focus group meeting was convened with the volunteer internees to assess how they felt the pilot scheme had fared overall, and its potential as a substitute for a real industrial placement. In addition, they were asked to complete a short synoptic questionnaire that sought to determine how they rated their employment skills before and after the pilot scheme. The answers in the synoptic questionnaire were ranked using a 5-point Likert scale of 1-5 with:

$$
\begin{aligned}
& 5=\text { Excellent } \\
& 4=\text { Good } \\
& 3=\text { Fair }
\end{aligned}
$$


$2=$ Poor

$1=$ Very poor

\subsection{Volunteer Intern Feedback}

Table 2 shows the averaged responses to the feedback questionnaire based on the five interns who were active in the pilot scheme.

Table 2. Summary of virtual internees’ feedback from synoptic questionnaire set before and after the pilot scheme.

\begin{tabular}{|c|c|c|c|c|}
\hline \multirow{2}{*}{ Feedback Question } & \multirow{2}{*}{$\begin{array}{l}\text { Feedback Requested on } \\
\text { Topic/Activity/Scheme }\end{array}$} & \multicolumn{3}{|c|}{ Mean Score (Out of 5) } \\
\hline & & Before & After & Gain \\
\hline \multirow{3}{*}{$\begin{array}{l}\text { Please indicate your } \\
\text { Awareness of: }\end{array}$} & $\begin{array}{l}\text { Developer/Tenant/Design Team relationship } \\
\text { in building projects. }\end{array}$ & 2.8 & 3.6 & 0.8 \\
\hline & Local and National Planning Authorities. & 2.4 & 4.0 & 1.6 \\
\hline & Environmental Issues in building projects. & 2.4 & 4.0 & 1.6 \\
\hline \multirow{7}{*}{$\begin{array}{l}\text { Please rate your } \\
\text { Work Place Skills: }\end{array}$} & Working as a member of a team. & 4.0 & 4.2 & 0.2 \\
\hline & Using a project programme (GANTT) chart. & 3.6 & 4.2 & 0.6 \\
\hline & Business Letter-writing. & 3.0 & 4.0 & 1.0 \\
\hline & Technical report-writing. & 3.2 & 3.6 & 0.4 \\
\hline & Producing a meeting Agenda. & 2.0 & 3.4 & 1.4 \\
\hline & Producing Minutes of a meeting. & 2.0 & 3.6 & 1.6 \\
\hline & & \multicolumn{3}{|c|}{ Mean Score (Out of 5) } \\
\hline \multirow{4}{*}{ Please indicate: } & Ease of using SecondLife. & \multicolumn{3}{|c|}{2} \\
\hline & Usefulness of SecondLife. & \multicolumn{3}{|c|}{2.4} \\
\hline & Usefulness of the Virtual Placement Scheme. & \multicolumn{3}{|c|}{3.6} \\
\hline & $\begin{array}{c}\text { Potential for future Virtual Placement } \\
\text { Schemes in Civil Engineering. }\end{array}$ & \multicolumn{3}{|c|}{3.8} \\
\hline
\end{tabular}

During the focus group meeting, specific individual comments as useful feedback from the interns were noted. They are summarised in Table 3.

Table 3. Summary of outcomes of focus group meeting: Pros and cons of pilot scheme.

\begin{tabular}{cc}
\hline \multicolumn{1}{c}{ Positive Comments } & Negative Comments \\
\hline $\begin{array}{c}\text { SecondLife proved a good interface between } \\
\text { internees and scheme manager/s as long as high } \\
\text { performance hardware was available to operate it } \\
\text { efficiently. Skype video conferencing might also be } \\
\text { used in this regard. }\end{array}$ & $\begin{array}{c}\text { The tasks that were set could have been } \\
\text { more challenging. }\end{array}$ \\
\hline $\begin{array}{c}\text { The virtual internship scheme was okay for first } \\
\text { year students. }\end{array}$ & $\begin{array}{c}\text { More direction was required by the interns to } \\
\text { allow them to carry out the detailed } \\
\text { tasks effectively. }\end{array}$ \\
\hline $\begin{array}{c}\text { Students were provided with sufficient supporting } \\
\text { documentation and information under this scheme. }\end{array}$ & $\begin{array}{c}\text { Technical problems experienced with } \\
\text { SecondLife limited its usefulness. }\end{array}$ \\
\hline
\end{tabular}


Table 3. Cont.

\begin{tabular}{cc}
\hline \multicolumn{1}{c}{ Positive Comments } & Negative Comments \\
\hline $\begin{array}{c}\text { The pilot internship scheme did give one a feel for } \\
\text { what working on a real life project was, especially } \\
\text { at such an early stage in their academic course. }\end{array}$ & $\begin{array}{c}\text { Lack of interaction between interns in } \\
\text { SecondLife did not help in promoting the } \\
\text { realness of the scheme. }\end{array}$ \\
\hline $\begin{array}{c}\text { For group work, the interns progressively dropping } \\
\text { out of the scheme at short notice mimicked real } \\
\text { life projects. }\end{array}$ & $\begin{array}{c}\text { Lack of body language in SecondLife was also } \\
\text { a problem. This would not be the case if Skype } \\
\text { video conferencing was also used. }\end{array}$ \\
\hline & $\begin{array}{c}\text { Interns should be given more choice on what } \\
\text { aspect of project they might want to work on. }\end{array}$ \\
\hline
\end{tabular}

\subsection{Tutor's Observations}

In general, the tutor observed that apart from the technical difficulties experienced with SecondLife and within the virtualBrunel workspace, the virtual environment prevented real interaction between the users, and thus limited its suitability for this type of scheme. In particular the following specific issues were noted:

- Avatars were difficult to recognise and could not easily be associated with actual individual interns.

- There was no body-language to discern.

- There was a perceived loss of reality and therefore commitment i.e., "this is not a real project nor is it my real boss/tutor so why take it seriously?”

Additionally, the tutor found that attempting to arrange virtual meetings proved very difficult in practice. This was due to interns having job/family commitments or being on holiday. The type of work some of the interns were doing involved late evenings and weekends whilst others worked during normal daylight hours. This severely limited the number of meetings and was almost certainly a factor in interns dropping out of the scheme. Whilst this also created some difficulties in interns working as a team, it was noticeable that interns were reluctant to contact each other and share information. There appeared to be a lack of initiative by the interns in finding information and seeking solutions. In some instances this even extended to them not reading the information they were given beforehand.

He further noted that the starting basic skills level of the interns varied considerably. This resulted in some interns considering that tasks were too simple or mundane whilst others struggled on the same tasks. A considerable amount of administrative work, time and resources was involved when organising virtual meetings and providing feedback on tasks. Any full scale scheme would need full administrative and managerial support to operate adequately.

\subsection{Summary of Pilot Scheme Outcomes}

This pilot involved five volunteer interns working on a virtual placement scheme over the summer recess. All were geographically separated and had either work/employment and/or holiday commitments. A project had been created as a vehicle for the scheme and this required a number of tasks to be carried out by the intern/s. The intention was to create a realistic project that would help improve basic 
employment skills relevant to graduate civil engineers and that could be undertaken without the interns having to be present at the same place and time.

The aim of pilot scheme was to assess the viability of the idea of a virtual placement using a small group of volunteer first year undergraduates. Whilst this involved them carrying out the tasks, the aim was not to provide them with a full virtual internship. This was explained carefully to the volunteers. It inevitably limited the amount of time and effort they expended on the scheme. The tasks set for the interns were estimated to require about two weeks work, but spread out over a three month period i.e., a weekly combined scheme involvement of about one day per week.

Initially use was made of SecondLife as a virtual, web-based environment in which to hold meetings. Most universities are showing a keen interest in the potential use of SecondLife in education (since people of university age are now readily familiar with such technology). However, as other academics have found [28], technical difficulties were experienced in using SecondLife that made holding meetings very difficult. Also the virtual environment cannot convey the sense and seriousness of a real project meeting. Neither can it provide the level of interaction of a real meeting [18].

Some of the interns felt that Skype video conferencing would provide a more suitable medium. However, even with Skype, experience has shown it can be of limited use when dealing with a group of geographically separated people and requires a high standard of internet connectivity. The tutor has experience of using commercially available software for video conferencing in the business world. This is far superior and allows the exchange of documents during the meeting. On the other hand it is expensive and generally requires specialist hardware [28]. Nevertheless, if virtual placements are to be undertaken in future that involves group work, than some video conferencing facilities should be investigated.

The results from the intern feedback session and questionnaire show that on the whole, the volunteer interns were optimistic about the potential for virtual placements and that the approach used was generally suitable for first year undergraduates. However, the responses as to the operation of the scheme were conflicting with some volunteer's feeling that the tasks were too simplistic and others that more detailed guidance was required. This possibly reflected the wide range of existing skills amongst the group. It is recommended therefore that in any future virtual placement, tasks be differentiated in terms of difficulty to suit individual internees.

The self-assessed results show an improvement in skills of the interns following the completion of the scheme. It must be borne in mind when looking at these results that the aim was to assess the viability of future virtual placements, not provide real work-based placements for the volunteers after completion of the pilot scheme. As a result, tasks were mostly not completed. It was therefore pleasing to see a significant improvement in self-perceived skills.

The scheme resulted in a considerable work load for the tutor including the chairing of virtual meetings at unsociable hours. Extensive feedback was required on work submitted by the volunteer interns. The amount of work would be expected to increase in a real "virtual" placement as interns would be more committed and produce more work in a timely manner. 


\subsection{Future Work Needed to Implement a Full Scale Virtual Internship Scheme}

It is hoped that due to the successful implementation of this pilot scheme, it could be duplicated to other Departments within the College of Engineering, Design and Physical Sciences. Some of the existing developed material could be used, whilst other more discipline specific material would need to be developed.

For a future larger scheme of this nature, it is recommended that it is important that the student's own Civil and Environmental Engineering Society at Brunel University would be involved from the start in this full scale version with selected students forming part of the Materials Development Committee thus ensuring all assignments were at the appropriate level. The scheme would be named after the main employer sponsor (which still needs to be sought), and this means that by going on it, this scheme would also enhance the student's CVs by linking it to a major employer as sponsor.

Any future full scale scheme would need to be entirely optional even though all students would be briefed on it during their formally academic Professional Skills module. This is so that only highly motivated students would apply on an official application form. Thus they would have to prove their drive and commitment by justifying their inclusion as part of the application process since intern places would be limited. After the exam period and after the Board of Studies meeting, the academic performance in the first year would also be taken into account when short listing candidates for the scheme. There would also have to be clear selection criteria that students are aware of. They would need to see this scheme as a highly competitive process in order that only serious students applied. Selected candidates when signing up for this scheme would need to guarantee their seriousness of involvement in it otherwise the participant's place would be cancelled and offered elsewhere if they did not immediately engage in it by submitting assignments on time.

During the pilot phase of this project, no actual credits were awarded to students to undertake this scheme as occurs with student's undertaking an official work placement as part of their sandwich course. However long term wise it may be a good strategy to be used in order to get first year student's to engage with this proposed process effectively. This would mean developing this scheme as an optional credit module that ran over the summer period. Thus it would need to be accredited by the University as part of the potential learning outcomes for student's undertaking these courses.

Assessment of the extended version of this scheme should be measured in three ways. Firstly the overall student satisfaction would be measured in a similar manner to the pilot version by using questionnaires and, potentially, focus groups. Then a synoptic testing would be used to ascertain skills development by test-retesting before and after the "virtual" placement. Finally objective measurement targets would be considered such as any increase in the number of placement applications per year; any increase in the number of sandwich placements per year; and any increase in the number of final year students being offered firm graduate engineering job offers before their final exams; and also any an increase in all final year students six months after having completed their degree.

At the end of the placement all successful participants would receive a Certificate of Participation. In the short term, this scheme could be potentially part run and administered by taught post graduate students who would help deliver this scheme across the summer with their benefit being gaining points under a small 5 credit optional module on this scheme. They could also be used in the role playing scenarios especially the more mature postgraduate students who had existing engineering work 
experience and skills. They would gain valuable leadership skills and abilities, and also it would address part of their professional development objectives. Long term wise this scheme if successful would probably need dedicated administrative personnel to run it.

Resource personnel producing the material for the full scale version of this scheme need to also address the following questions:

- What tasks that will be required from each intern and what responsibilities are involved?

- Will training or supervision be offered at the beginning or over the course of the placement/internship? Will interns be able to use this as a reference once the internship is over?

- How many hours per week are required for the internship?

- How will it be evaluated for effectiveness at the end of the internship?

\section{Conclusions}

In summary, it appears that this virtual training approach may prove a cost effective way of letting students gain an insight into the workplace whilst improving their employability skills during a very early stage of their studies. It may also prove a way for employers to select, from a large range of students, the best to actually undertake their real work-based internships as part of their sandwich course. However, care is needed in scheme set-up to ensure that it is fully resourced in terms of technical content, administrative personnel and internet connectivity links, both in terms of hardware and software provision. It is also important that the internship assignments and tasks set are of a highly relevant nature and pitched at a suitable level.

\section{Acknowledgments}

The specific research work mentioned in this briefing note was carried out by Brunel University's Civil Engineering Division and was funded by the University's Teaching and Learning Innovative Fund. The author would like to thank Olinkha Gustafson-Pearce from the Design Department for her assistance on the project work especially her work using the virtualBrunel platform and SecondLife. The author would also like to acknowledge the work carried out by the engineering consultant/tutor who was specifically hired to manage the pilot scheme, namely, Martin Ratcliffe.

\section{Conflicts of Interest}

The author declares no conflict of interest.

\section{References}

1. Reed, B.; Coates, S.; Odhiambo, F.; Kayaga, S. Training for real: Matching employer needs to training supply. Proc. Inst. Civ. Eng. Munic. Eng. J. 2011, 164, 269-278.

2. Martin, W.C.; Ashurst, J. Future skill sets for the municipal engineer. Proc. Inst. Civ. Eng. Munic. Eng. J. 2011, 164, 241-250.

3. Institute of Directors (IOD). Graduates' employability skills, IOD skills briefing-December 2007. Available online: http://www.iod.com/influencing/policy-papers/education-andskills/graduates-employability-skills (accessed on 27 February 2015). 
4. Zaharim, A.; Yuzainee, M.D.Y; Mohd, Z.O.; Azah, M.; Norhamidi, M. Engineering Employability Skills Required by Employers in Asia. In Proceedings of the 6th WSEAS International Conference on Engineering Education, Stevens Point, WI, USA, 22-24 July 2009.

5. Brown, P.; Lauder, H.; Ashton, D. Education, Globalisation and the Future of the Knowledge Economy. Eur. Educ. Res. J. 2008, 7, 131-156.

6. Blom, A.; Saeki, H. Employability and skill set of newly graduated engineers in India. In Policy Research Working Paper 5640; World Bank: Washington, DC, USA, 2011. Available online: http://documents.worldbank.org/curated/en/2011/04/14103800/employability-skill-set-newlygraduated-engineers-india (accessed on 16 March 2015).

7. Bather, M. Students' views on their education and the future. Proc. Inst. Civ. Eng. Munic. Eng. J. 2011, 164, 209-219.

8. Archer, W.; Davison, J. Graduate Employability: What do Employers Think and Want. Consultant Report; The Council for Industry and Higher Education: London, UK, 2008.

9. Clarke, B. Industry needs to pay more to educate engineers for a low-carbon future. Proc. Inst. Civ. Eng. Civ. Eng. J. 2010, 163, 102-102.

10. Jennings, A. Integrating communication skills into civil engineering education. Proc. Inst. Civ. Eng. Civ. Eng. J. 1996, 114, 73-80.

11. Jennings, A.; Ferguson, J.D. Discussion note: Integrating communication skills into civil engineering education. Proc. Inst. Civ. Eng. Civ. Eng. J. 1997, 120, 36-37.

12. Pender, G.; Stewart, B.; Agar, A.; Ervine, A.; Boyce, D. Developing innovative problem solving skills in undergraduates. Proc. Inst. Civ. Eng. Civ. Eng. J. 1999, 132, 96-102.

13. Bell, M.W. Toward a Definition of "Virtual Worlds". J. Virtual Worlds Res. 2008, 1, 1-5. Available online: https://journals.tdl.org/jvwr/index.php/jvwr/article/view/283/237 (accessed on 17 March 2015).

14. Hew, K.F.; Cheung, W.S. Use of Three-Dimensional (3-D) Immersive Virtual Worlds in K-12 and Higher Education Settings: A Review of the Research. Br. J. Educ. Technol. 2010, 41, 33-55.

15. Kirriemuir, J., ed. Virtual world activity in UK universities and colleges: An academic year of expectation? Snapshot 7; Eduserv Foundation: Bath, UK, 2009. Available online: http://www.silversprite.com/ss/wp-content/uploads/2014/10/snapshot-seven.pdf (accessed on 17 March 2015).

16. Kluge, S.; Riley, L. Teaching in Virtual Worlds: Opportunities and Challenges. Issues Inform. Sci. Inf. Technol. 2008, 5, 127-135.

17. Mili, F.; Barr, J.; Harris, M.; Pittiglio, L. Nursing training: 3D game with learning objectives. In Proceedings of the 2008 First International Conference on Advances in Computer-Human Interaction, Sainte Luce, Martinique, France, 10-15 February 2008.

18. Wood, D. Experiential learning through "real world” placements undertaken in 3D "virtual world" spaces. In Proceedings of the 26th Ascilite Conference, Auckland, New Zealand, 2009; pp. 1121-1129. Available online: http://www.ascilite.org/conferences/auckland09/procs/wood.pdf (accessed on 17 March 2015).

19. Patterson, A.M. Everything you need to know about virtual internships. USA Today College, 2015. Available online: http://ups.uloop.com/news/view.php/704/Everything-you-need-to-know-about-virtual (accessed on 27 February 2015). 
20. Khalid, S. Briefing: Virtual service overseas: A new way to volunteer. Proc. Inst. Civ. Eng. Civ. Eng. J. 2006, 159, 53-53.

21. Attwood, R.; Tahir, T. UK fails to integrate overseas students. Times Higher Educational Supplement, 2007. Available online: http://www.timeshighereducation.co.uk/news/uk-fails-tointegrate-overseas-students/310723.article (accessed on 27 February 2015).

22. Lizzio, A.; Wilson, K. Action learning in higher education: An investigation of its potential to develop professional capability. Stud. High. Educ. 2004, 29, 469-488.

23. Yeo, R. "Problem-based learning: A suitable approach in tertiary education?” In Problem-Based Learning: New Directions and Approaches, Temasek Centre for Problem Based Learning; Tan, K., Mok, J., Lee, M., Ravindran, R., Eds.; Temasek Centre for Problem Based Learning: Singapore City, Singapore, 2005; 93-113.

24. Revans, R. Action Learning: New Techniques for Management; Blond \& Briggs, Ltd.: London, UK, 1980.

25. Kolb, D.A. Experiential Learning: Experience as the Source of Learning and Development; Prentice-Hall: Englewood Cliffs, NJ, USA, 1984.

26. Revans, R.W. ABC of Action Learning; Lemos and Crane: London, UK, 1998.

27. McGill, I.; Beaty, L. Action Learning: A Practitioner's Guide, 2nd ed.; Routledge: Oxford, UK, 2001.

28. Kirriemuir, J. UK university and college technical support for Second Life developers and users. Educ. Res. 2010, 52, 215-227.

29. Radford, M.; Vlachantoni, A.; Evandrou, M.; Schröder-Butterfill, E. A Literature Review on the Usefulness of Second Life as a Pedagogic Tool in the Postgraduate Teaching of Gerontology and Other Policy Relevant Social sciences in the UK. In CRA Discussion Paper No. 1102; Centre for Research on Ageing (CRA): Faculty of Social and Human Sciences, University of Southampton, UK, December 2011.

30. Linden Lab. The Virtual Work Advantage. In Second Life Work Brochure; Linden Research, Inc.: San Francisco, CA, USA, 2011. Available online: http://lecs-static-secondlifecom.s3.amazonaws.com/work/SL-Work-Brochure-010411.pdf (accessed on 17 March 2015).

31. Broadribb, S.C.; Carter, C.J.P. Using Second Life in Human Resource Development. Br. J. Educ. Technol. 2009, 40, 547-550.

32. Good, J.; Howland, K.; Thackray, E. Problem-Based Learning Spanning Real and Virtual Worlds: A Case Study in Second Life. ALT-J. 2008, 16, 163-172.

33. Wearne, S. Professional engineers' needs for managerial skills and expertise. Proc. Inst. Civ. Eng. Civ. Eng. J. 2004, 157, 44-48.

(C) 2015 by the authors; licensee MDPI, Basel, Switzerland. This article is an open access article distributed under the terms and conditions of the Creative Commons Attribution license (http://creativecommons.org/licenses/by/4.0/). 